\title{
Knowledge and attitudes towards cardiopulmonary resuscitation and defibrillation amongst Asian primary health care physicians
}

This article was published in the following Dove Press journal:

Open Access Emergency Medicine

16 November 2009

Number of times this article has been viewed

\author{
Marcus EH Ong' \\ Susan Yap' \\ Kim P Chan' \\ Papia Sultana ${ }^{2}$ \\ Venkataraman Anantharaman' \\ 'Department of Emergency Medicine, \\ ${ }^{2}$ Department of Clinical Research, \\ Singapore General Hospital, Singapore
}

Correspondence: Marcus EH Ong c/o Department of Emergency Medicine, Singapore General Hospital, Outram

Road, Singapore 169608

Tel +6563213590

Fax +6563214873

Email marcus.ong.e.h@sgh.com.sg
Objective: To assess the knowledge and attitudes of local primary health care physicians in relation to cardiopulmonary resuscitation (CPR) and defibrillation.

Methods: We conducted a survey on general practitioners in Singapore by using a self-administered questionnaire that comprised 29 questions.

Results: The response rate was $80 \%$, with 60 of 75 physicians completing the questionnaire. The average age of the respondents was 52 years. Sixty percent of them reported that they knew how to operate an automated external defibrillator (AED), and $38 \%$ had attended AED training. Only 36\% were willing to perform mouth-to-mouth ventilation during CPR, and 53\% preferred chest compression-only resuscitation (CCR) to standard CPR. We found those aged $<50$ years were more likely to be trained in basic cardiac life support (BCLS) $(P<0.001)$ and advanced cardiac life support $(P=0.005)$ or to have ever attended to a patient with cardiac arrest $(P=0.007)$. Female physicians tended to agree that all clinics should have AEDs $(P=0.005)$ and support legislation to make AEDs compulsory in clinics $(P<0.001)$. We also found that a large proportion of physicians who were trained in BCLS $(P=0.006)$ were willing to perform mouth-to-mouth ventilation.

Conclusion: Most local primary care physicians realize the importance of defibrillation, and the majority prefer CCR to standard CPR.

Keywords: general practitioners, cardiac arrest, resuscitation, defibrillation, attitude, knowledge

\section{Introduction}

General practitioners (GPs) can play an important role in the management of out-of-hospital cardiac arrest (OHCA). ${ }^{1,2} \mathrm{OHCA}$ is an international health issue, and the reported survival rates after OHCA vary greatly. ${ }^{3}$ The 'chain of survival' concept ${ }^{4}$ states that the survival of patients with OHCA can be improved by early access, early cardiopulmonary resuscitation (CPR), early defibrillation, and early advanced care. Current research indicates that shorter response times, ${ }^{5}$ early $\mathrm{CPR},{ }^{6,7}$ and early defibrillation do indeed improve patient survival. ${ }^{8,9}$ GPs may witness a cardiac arrest in primary health care clinics or during a home visit, and early defibrillation by GPs has been shown to improve the outcomes of OHCA. ${ }^{10}$ Programs have been created to teach GPs to use defibrillators and actively participate in resuscitation. ${ }^{10}$

Singapore is a multicultural city-state that has a population of 4.6 million $^{11}$ and is situated in southeast Asia. The island's emergency medical services system is primarily a single-tier system that is equipped to provide basic life support and defibrillation with automated external defibrillators (AEDs). Singapore's primary health care system 
is composed of both public and private sectors. The public sector comprises 18 government-related polyclinics, with 4-10 doctors in each clinic. In contrast, the private sector consists of mostly single-doctor clinics, with family as well as corporate practices. The survival rate after OHCA in Singapore has been reported to be $2.0 \% .^{12}$

Although several studies have been conducted on public knowledge regarding and attitudes towards CPR and defibrillation, ${ }^{13-15}$ very little is known about physicians' attitudes towards resuscitation. We conducted a self-reported survey to assess the experience, knowledge, and attitudes of local primary health care doctors towards resuscitation. On the basis of the knowledge obtained, we hope to propose a program to encourage the active participation of GPs in the management of $\mathrm{OHCA}$.

\section{Methods}

We conducted an 'opportunistic' survey of primary healthcare doctors working in both the private and public sectors. This survey was conducted in conjunction with a symposium organized for GPs on 'Common Pitfalls When Dealing with Medical Emergencies in Family Practice'. The survey questionnaire consisted of 29 questions and was selfadministered (Appendix 1). This questionnaire had been designed by the study team and had been validated in a pilot study. It was divided into four sections: demographics, knowledge, attitudes, and chest compression-only resuscitation (CCR) versus CPR.

Besides questions on the background characteristics of the doctors, the respondents were also asked if they had attended to any patient with cardiac arrest and if they had access to a defibrillator in their area of practice.

In the knowledge section, respondents were asked to answer a series of five questions regarding defibrillation. Respondents were also asked if they had attended any training on AEDs and whether they knew how to operate an AED.

The attitudes section determined the following: (1) whether or not the respondents would use an AED, if available, to treat a patient with cardiac arrest; (2) the respondents' confidence level in using AEDs; (3) whether the respondents agreed that all primary health care clinics should be equipped with AEDs; (4) whether they would support legislation to make AEDs compulsory equipment in all clinics; and (5) whether they would consider buying AEDs and at what cost.

In the last section (CCR vs CPR), respondents were asked if they were willing to perform mouth-to-mouth ventilation during CPR and which method of resuscitation they preferred, CCR or standard CPR.

Descriptive statistics with frequency tables were computed using SPSS software (v. 17.0 SPSS Inc., Chicago, IL, USA). To determine the association between the demographics of the study population and their knowledge and attitude, continuous variables and multinomial variables were recoded into two groups according to the following standard cut-off points. Age groups were created according to the median age ('below 50 years' and '50 years and above'); the level of confidence in using AEDs was grouped as 'below and equal to score 5' and 'above 5'; specialist training was re-categorized into 'family medicine' and 'other', and the type of practice, into 'family practice' and 'other'. A contingency coefficient which indicated the level of association, such as the Pearson correlation coefficient, and the $P$-values for Fisher's exact test (because the sample size was small) were calculated. Statistical significance was set at $P<0.05$.

\section{Results}

We issued a total of 75 forms to all the attendees of the symposium. Of these, 60 responded, giving a response rate of $80 \%$. The demographic characteristics of the respondents are shown in Table 1. The average age of the respondents was 52 years, and $43 \%$ of them were male. The mean duration for which the physicians had been in practice was 28 years. Further, 29\% had a valid basic cardiac life support (BCLS) certificate, and $21 \%$ had a valid advanced cardiac life support (ACLS) certificate. We found that $27 \%$ of the respondents had defibrillators in their clinics.

With regard to the knowledge about defibrillation, only $37 \%$ of the respondents correctly answered all five questions on defibrillation (Table 2 ). We found that $92 \%$ correctly identified defibrillation as one of the most important interventions in cardiac arrest. Sixty percent reported that they knew how to operate an AED, and $38 \%$ had attended training on AEDs. However, only $42 \%$ of the respondents knew what 'AED' stood for.

The responses to questions regarding attitudes towards resuscitation are shown in Table 3. Of the respondents, 93\% reported that if an AED were available, they would use it to treat cardiac arrest. Forty-six percent were willing to purchase an AED, and $62 \%$ agreed that all clinics should have defibrillators. However, only $36 \%$ would support legislation to make defibrillators compulsory in clinics. The confidence levels of the respondents in using AEDs are shown in Figure 1.

As shown in Table 4, only 36\% would perform mouth-to-mouth ventilation during $\mathrm{CPR}$, and 53\% preferred 
Table I Characteristics of respondents

\begin{tabular}{|c|c|}
\hline Characteristics & \\
\hline Mean age $(S D)(n=59)$ & $52(10.9)$ \\
\hline Male & $73 \%(43 / 59)$ \\
\hline \multicolumn{2}{|l|}{ Race } \\
\hline Chinese & $92 \%(54 / 59)$ \\
\hline Indian & $3 \%(2 / 59)$ \\
\hline Others & $5 \%(3 / 59)$ \\
\hline Mean years of practice $(S D)(n=59)$ & $27.9(10.6)$ \\
\hline \multicolumn{2}{|l|}{ Specialist training } \\
\hline Family medicine & $55 \%(33 / 60)$ \\
\hline Internal medicine & $3 \%(2 / 60)$ \\
\hline Nil & $42 \%(25 / 60)$ \\
\hline \multicolumn{2}{|l|}{ Type of practice } \\
\hline Family & $86 \%(52 / 60)$ \\
\hline Company & $12 \%(7 / 60)$ \\
\hline Industrial & $2 \%(1 / 60)$ \\
\hline Trained in BCLS & $6 \%(36 / 60)$ \\
\hline Valid BCLS certificate & $29 \%(10 / 34)$ \\
\hline Trained in ACLS & $32 \%(19 / 60)$ \\
\hline Valid ACLS certificate & $21 \%(4 / 19)$ \\
\hline Ever attended patients with cardiac arrest & $63 \%(38 / 60)$ \\
\hline \multicolumn{2}{|l|}{ No. of cardiac arrest cases attended } \\
\hline 1 & $18 \%(7 / 38)$ \\
\hline 2 & $21 \%(8 / 38)$ \\
\hline 3 & $5 \%(2 / 38)$ \\
\hline 4 & $3 \%(1 / 38)$ \\
\hline 5 & $5 \%(2 / 38)$ \\
\hline$\geq 10$ & $13 \%(5 / 38)$ \\
\hline Unknown & $34 \%(13 / 38)$ \\
\hline Has an AED in clinic & $27 \%(16 / 59)$ \\
\hline $\begin{array}{l}\text { Used clinic's AED on cardiac arrest } \\
\text { patient }(\%)(n=16)\end{array}$ & $6 \%(1 / 16)$ \\
\hline
\end{tabular}

Abbreviations: ACLS, advance cardiac life support; AED, automated external defibrillator; BCLS, basic cardiac life support; SD, standard deviation.

CCR to standard CPR. The reasons given for preferring CCR were that (1) CCR was, in the respondents' opinion, as effective as CPR (77\% agreed), (2) easier to learn (35\% agreed), and (3) the respondents were unwilling to perform mouth-to-mouth ventilation ( $31 \%$ agreed).

The associations between the demographics of the study population and their knowledge and attitudes are summarized in Tables 5 and 6.

We found that the responses to the items 'trained in BCLS,' 'trained in ACLS,' and 'ever attended to patients with cardiac arrest' significantly differed with age. We found that $90 \%$ of those aged less than 50 years were trained in BCLS, whereas only $31 \%$ of those aged 50 years or more had undergone BCLS training (contingency coefficient $=0.517, P<0.001$ ).
Table 2 Respondents' knowledge in defibrillation

\begin{tabular}{|c|c|}
\hline Knowledge & $\%(n)$ \\
\hline \multicolumn{2}{|l|}{$\begin{array}{l}\text { Obtained correct answer to the following } \\
\text { questions: }\end{array}$} \\
\hline $\begin{array}{l}\text { QI. What does the abbreviation 'A' in "AED” } \\
\text { represent? }\end{array}$ & $67 \%(40 / 60)$ \\
\hline $\begin{array}{l}\text { Q2. What does the abbreviation 'E' in "AED" } \\
\text { represent? }\end{array}$ & $50 \%(30 / 60)$ \\
\hline $\begin{array}{l}\text { Q3. What does the abbreviation 'D' in "AED" } \\
\text { represent? }\end{array}$ & $93 \%(56 / 60)$ \\
\hline $\begin{array}{l}\text { Q4. AED operator is not required to interpret } \\
\text { ECG rhythm }\end{array}$ & $85 \%(5 I / 60)$ \\
\hline $\begin{array}{l}\text { Q5. Defibrillation is the most important } \\
\text { intervention in cardiac arrest }\end{array}$ & $92 \%(55 / 60)$ \\
\hline \multicolumn{2}{|l|}{$\begin{array}{l}\text { Total score (full score = five questions answered } \\
\text { correctly): }\end{array}$} \\
\hline 1 & $2 \%(1 / 60)$ \\
\hline 2 & $10 \%(6 / 60)$ \\
\hline 3 & $25 \%(15 / 60)$ \\
\hline 4 & $27 \%(16 / 60)$ \\
\hline 5 & $37 \%(22 / 60)$ \\
\hline Know how to operate AED & $60 \%(36 / 60)$ \\
\hline Attended AED training & $38 \%(23 / 60)$ \\
\hline
\end{tabular}

Further, $50 \%$ of the doctors who were aged $<50$ years were ACLS certified vs $32.2 \%$ of the doctors who were aged $\geq 50$ years (contingency coefficient $=0.361, P=0.005$ ). Finally, $80 \%$ of the doctors in the younger group had attended to a patient with cardiac arrest vs $44.8 \%$ in the older group (contingency coefficient $=0.342, P=0.007$ ).

The responses to the questions 'Do you agree that all clinics should have an AED?' $(P=0.005)$ and 'Would you support legislation to make AEDs compulsory in all clinics?' $(P<0.001)$ significantly differed with gender. The female GPs tended to agree that all clinics should have an AED ( $93 \%$ women vs $50 \%$ men; contingency coefficient $=0.360, P=0.005$ ). Similarly, more women than men ( $80 \%$ women vs $20 \%$ men; contingency coefficient $=0.486, P<0.001$ ) said that they would support legislation to make AEDs compulsory in all clinics. In addition, fewer women ( $63 \%$ women vs $95 \%$ men; contingency coefficient $=0.392, P=0.003$ ) practiced in a family medicine setting rather than a company or an industrial setting.

Fifty percent of those trained in BCLS and 14\% of those not trained in BCLS (contingency coefficient $=0.345, P=0.006$ ) were willing to perform mouth-to-mouth ventilation.

Further, $70 \%$ of those with a valid BCLS certificate and $22 \%$ of those without a valid BCLS certificate said that they would support legislation to make AEDs compulsory in all clinics (contingency coefficient $=0.419, P=0.016$ ). Similarly, $70 \%$ of the GPs who practiced family medicine 
Table 3 Respondents' attitudes towards defibrillation

\begin{tabular}{|c|c|}
\hline \multicolumn{2}{|l|}{ Attitudes } \\
\hline $\begin{array}{l}\text { Willing to use AED to attend to cardiac arrest patient if it } \\
\text { is available }\end{array}$ & $93 \%(53 / 57)$ \\
\hline \multicolumn{2}{|l|}{ Reasons for not using AED: } \\
\hline Don't know what an AED is & 0 \\
\hline Don't know how to use AED & $100 \%(4 / 4)$ \\
\hline Fear of legal liability & 0 \\
\hline Not confident & 0 \\
\hline Willing to purchase AED & $46 \%(26 / 56)$ \\
\hline \multicolumn{2}{|l|}{ Willing to pay: } \\
\hline$<\$ 1,000(<\text { US dollar 695 })^{\mathrm{a}}$ & $44 \%(10 / 23)$ \\
\hline$\$ 1,000-2,999$ (US dollar 695-2,078) ${ }^{\mathrm{a}}$ & $30 \%(7 / 23)$ \\
\hline$\$ 3,000-4,999$ (US dollar $2,080-3,465)^{\mathrm{a}}$ & $22 \%(5 / 23)$ \\
\hline$>\$ 5,000$ (> US dollar 3,465) & $4 \%(1 / 23)$ \\
\hline \multicolumn{2}{|l|}{ Not willing to purchase AED because: } \\
\hline Expensive & $69 \%(20 / 29)$ \\
\hline Not useful & 0 \\
\hline Difficult to maintain & $3 \%(1 / 29)$ \\
\hline Unsure how to use & $3 \%(1 / 29)$ \\
\hline Others & $24 \%(7 / 29)$ \\
\hline \multicolumn{2}{|l|}{ Would be encouraged to purchase AED if: } \\
\hline Reasonable price & $89 \%(48 / 54)$ \\
\hline Easy to use & $32 \%(17 / 54)$ \\
\hline Easy to maintain & $30 \%(16 / 54)$ \\
\hline Others & $4 \%(2 / 54)$ \\
\hline Willing to attend AED course at own expense & $52 \%(28 / 54)$ \\
\hline Agreed that all clinics should have AED & $62 \%(34 / 55)$ \\
\hline $\begin{array}{l}\text { Would support legislation to make AED compulsory } \\
\text { equipment in all clinics }\end{array}$ & $36 \%(20 / 56)$ \\
\hline
\end{tabular}

Note: amount in Singapore dollars.

Abbreviations: AED, automated external defibrillator; CPR, standard cardiopulmonary resuscitation. and $30 \%$ of those who practiced in other settings (contingency coefficient $=0.317, P=0.019$ ) said that they would support the above legislation.

\section{Discussion}

This study was an opportunistic survey on resuscitation in the primary health care setting. We found that most primary care physicians realized the importance of defibrillation. However, only $27 \%$ had defibrillators in their clinics, and $38 \%$ had attended training on AEDs. The commonest reason for not purchasing an AED was the perception that it was expensive (65\%). Further, only $36 \%$ of the GPs said they would perform mouth-to-mouth ventilation during CPR, and 53\% preferred CCR to standard CPR.

We found that those aged $<50$ years were more likely to be trained in BCLS $(P<0.001)$ or ACLS $(P=0.005)$ and to have ever attended to a patient with cardiac arrest $(P=0.007)$. This finding might be related to the introduction of BCLS training for medical students in the 1980s and ACLS for residents in the 1990s. We also found that a large proportion of doctors who were trained in BCLS $(P=0.006)$ were willing to perform mouth-to-mouth ventilation. It is not surprising that BCLS or ACLS training did not have any effect on the respondents' confidence in handling an AED because in Singapore, AED training was only recently incorporated into BCLS training.

The female respondents tended to agree that all clinics should have AEDs $(P=0.005)$ and to support legislation to make AEDs compulsory $(P<0.001)$. This is an interesting finding that we cannot fully explain.

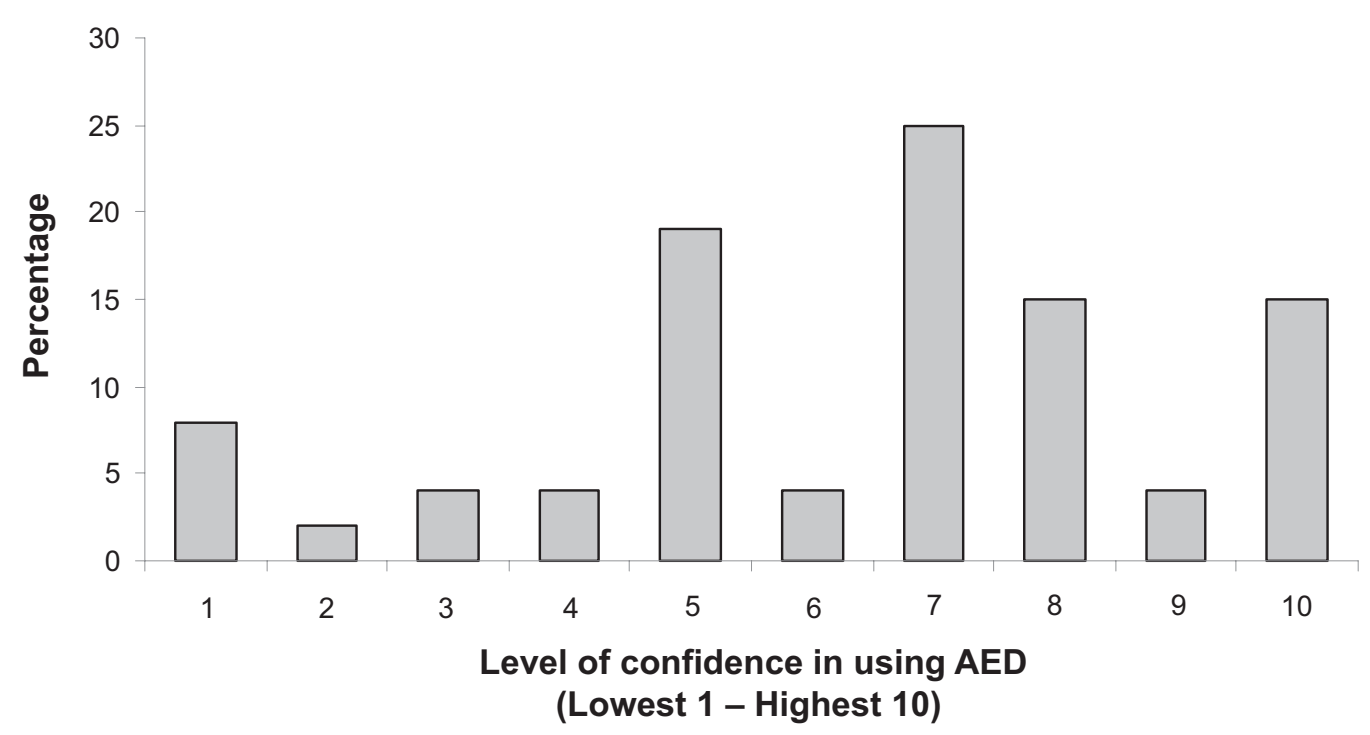

Figure I Level of confidence in operating an automated external defibrillator (AED). 
Table 4 Comparison between chest compression-only resuscitation and standard cardiopulmonary resuscitation

\begin{tabular}{ll}
\hline CCR vs. CPR & \\
\hline Would perform mouth-to-mouth & $36 \%(2 \mathrm{I} / 60)$ \\
ventilation during CPR & \\
Preferred method of resuscitation & \\
CCR & $53 \%(27 / 5 I)$ \\
CPR & $47 \%(24 / 51)$ \\
Preferred CCR because: & \\
As effective as CPR & $77 \%(20 / 26)$ \\
Easier to learn & $35 \%(9 / 26)$ \\
Unwilling to do mouth-to-mouth & $31 \%(8 / 26)$ \\
Preferred CPR because: & \\
$\quad$ More effective & $70 \%(16 / 23)$ \\
Confident of CPR technique & $9 \%(2 / 23)$ \\
Recommended by National & $39 \%(9 / 23)$ \\
Resuscitation Council &
\end{tabular}

Abbreviations: $C C R$, chest compression-only resuscitation; CPR, standard cardiopulmonary resuscitation.

GPs play an important role in managing OHCA. In a previous study, we found that the incidence of cardiac arrest in primary health care facilities in Singapore was 1.12 per 100,000 people per year, and these arrests constituted $6.0 \%$ of all OHCAs in the country. ${ }^{16}$ GPs may witness an arrest in their clinic or during a house call, or they may be called upon to attend to a patient with cardiac arrest. ${ }^{1}$ Thus, it is possible for GPs to initiate CPR, defibrillation, or advanced life support before ambulance crews arrive and thereby improve the patient's chances of survival. ${ }^{10,17}$

The majority of GPs in Singapore work in a private practice, in a 'for profit' setting. Only $10 \%$ of primary health care providers in the country work in a public, subsidized care setting. This might explain the gap in the respondents' attitudes towards defibrillation and the low take-up of defibrillators by GPs. Current local regulations require all clinics to be equipped with drugs required for resuscitation (eg, epinephrine and atropine). However, there is currently no specification regarding defibrillators or airway equipment (eg, bag-valve mask devices). We found that cost and lack of confidence in using AEDs were the main reasons why GPs did not have defibrillators in their clinics. With the advent of low-cost defibrillators (less than $\$ 3000$ Singapore dollars, approximately $\$ 2,070$ US dollars), this barrier can possibly be overcome. The invention of AEDs has also simplified the technique of external defibrillation. ${ }^{18}$ These devices have been shown to be accurate and effective, ${ }^{19}$ and even nonmedical personnel can be successfully trained to use them. ${ }^{20,21} \mathrm{We}$ propose that legislation to make defibrillators mandatory clinic equipment, similar to emergency drugs, be introduced.

Table 5 Results from cross-table (contingency coefficient, $P$-value of Fisher's exact test)

\begin{tabular}{lll}
\hline & Age* & Gender \\
\hline Trained in BCLS & $0.517,<0.001$ & $0.096,0.556$ \\
Valid BCLS certificate & $0.234,0.225$ & $0.105,0.692$ \\
Trained in ACLS & $0.361,0.005$ & $0.069,0.755$ \\
Valid ACLS certificate & $0.258,0.530$ & $0.073,1.000$ \\
Specialist training (family medicine vs internal medicine/general surgery/others) & $0.183,0.195$ & $0.201,0.147$ \\
Type of practice (family vs company/industrial) & $0.188,0.254$ & $0.392,0.003$ \\
Ever attended cardiac arrest cases & $0.342,0.007$ & $0.158,0.241$ \\
Know to operate AED & $0.083,0.601$ & $0.116,0.552$ \\
Level of confidence in using AED & $0.035,1.000$ & $0.090,0.547$ \\
Willing to buy AED & $0.269,0.058$ & $0.252,0.071$ \\
Willing to use AED if available & $0.020,1.000$ & $0.173,0.315$ \\
Agreed that all clinics should have AED & $0.021,1.000$ & $0.360,0.005$ \\
Would support legislation to make AED compulsory in all clinics & $0.183,0.262$ & $0.486,<0.001$ \\
Would support/participate in community CPR/AED project & $0.102,0.529$ & $0.08 I, 0.730$ \\
Obtained total score & $0.083,0.596$ & $0.076,0.763$ \\
Would perform mouth-to-mouth ventilation during CPR & $0.179,0.266$ & $0.050,0.767$ \\
Preferred method of resuscitation (CCR vs CPR) & $0.125,0.407$ & $0.025, I .000$ \\
\hline
\end{tabular}

Note: *Comparison between age group $<50$ years and age group $\geq 50$ years.

Abbreviations: ACLS, advance cardiac life support; AED, automated external defibrillator; BCLS, basic cardiac life support; CCR, chest compression-only resuscitation; CPR, standard cardiopulmonary resuscitation. 
Table 6 Results from cross-table (Contingency coefficient, $P$-value of Fisher's exact test)

\begin{tabular}{|c|c|c|c|c|c|}
\hline & Trained in BCLS & $\begin{array}{l}\text { Valid BCLS } \\
\text { certificate }\end{array}$ & Trained in ACLS & $\begin{array}{l}\text { Valid ACLS } \\
\text { certificate }\end{array}$ & Type of practice \\
\hline Level of confidence in using AED & $0.131,0.382$ & $0.272,0.141$ & $0.005,1.000$ & $0.126,1.000$ & $0.208,0.232$ \\
\hline Willing to buy AED & $0.055,0.785$ & $0.273,0.141$ & $0.089,0.578$ & $0.225,0.582$ & $0.228,0.127$ \\
\hline Agreed that all clinics should have AED & $0.049,0.779$ & $0.253,0.245$ & $0.175,0.248$ & $0.015,1.000$ & $0.111,0.696$ \\
\hline Would support legislation & $0.038,0.781$ & $0.419,0.016$ & $0.095,0.561$ & $0.325,0.262$ & $0.317,0.019$ \\
\hline $\begin{array}{l}\text { Would perform mouth-to-mouth } \\
\text { ventilation during CPR }\end{array}$ & $0.345,0.006$ & $0.038,1.000$ & $0.160,0.254$ & $0.225,0.582$ & $0.093,0.698$ \\
\hline Preferred method of resuscitation & $0.120,0.558$ & $0.266,0.220$ & $0.243,0.136$ & $0.119,1.000$ & $0.146,0.425$ \\
\hline
\end{tabular}

Abbreviations: ACLS, advance cardiac life support; AED, automated external defibrillator; BCLS, basic cardiac life support; CPR, standard cardiopulmonary resuscitation.

We believe that with education and voluntary programs to subsidize purchase costs, more primary care physicians will support this move.

Recently, CCR without ventilations has been proposed as an alternative to standard CPR for bystanders. ${ }^{22}$ Proponents of CCR argue that it overcomes bystander reluctance to perform mouth-to-mouth ventilations ${ }^{23-31}$ and is simpler to teach, ${ }^{32-34}$ especially when giving instructions to an untrained bystander over the telephone. ${ }^{35-38}$ It may also result in fewer interruptions to chest compressions. ${ }^{39-42}$ Our study seems to indicate that the majority of GPs prefer CCR to standard CPR.

The limitations of this study include the small sample size and possible lack of a representative sample, which is attributable to the sampling method. Because this was an opportunistic survey, a systematic bias may have been introduced owing to the inherent interest of the physicians who attended the symposium in emergency medicine. However, it must be noted that defibrillation and CPR were not the focus of the symposium.

We intend to follow up this study with a national, population-based survey to determine the knowledge and attitudes of the public in relation to CPR and defibrillation. This survey will be linked to the national census process and will include a substudy on the knowledge and attitudes of medical practitioners.

\section{Conclusion}

In this study, we found that the majority of primary care physicians in Singapore realize the importance of defibrillation. Further, most physicians prefer CCR to standard CPR. This information will be useful in planning subsequent educational activities to encourage CPR and defibrillation by GPs.

\section{Disclosures}

This paper was presented at the Society for Emergency Medicine in Singapore 10th Annual Scientific Meeting, Singapore in February 2009 and at the Singapore General Hospital 18th Annual Scientific Meeting, Singapore in April 2009. The authors report no conflicts of interest in this work.

\section{References}

1. Pai GR, Haites NE, Rawles JM. One thousand heart attacks in Grampian: the place of cardiopulmonary resuscitation in general practice. $\mathrm{Br} \mathrm{Med}$ $J$ (Clin Res Ed). 1987;294(6568):352-354.

2. Soo L, Smith N, Gray D. The place of general practitioners in the management of out-of-hospital cardiopulmonary resuscitation. Resuscitation. 1999;43(1):57-63.

3. Eisenberg MS, Hortwood BT, Cummins RO, Reynolds-Haertle R, Hearne TR. Cardiac arrest and resuscitation: a tale of 29 cities. Ann Emerg Med. 1990;19(2):179-186.

4. Cummins RO, Ornato JP, Thies WH, Pepe P. Improving survival from sudden cardiac arrest: the "chain of survival" concept. Circulation. 1991;83(5):1832-1847.

5. Pell JP, Sirel JM, Marsden AK, Ford I, Cobbe SM. Effect of reducing ambulance response times on deaths from out of hospital cardiac arrest: cohort study. BMJ. 2001;322(7299):1385-1388.

6. Martens PR, Mullie A, Calle P, Van Hoeyweghen R. Influence on outcome after cardiac arrest of time elapsed between call for help and start of bystander basic CPR. The Belgian Cerebral Resuscitation Study Group. Resuscitation. 1993;25(3):227-234.

7. Cummins RO, Eisenberg MS, Hallstrom AP, Litwin PE. Survival of out-of-hospital cardiac arrest with early initiation of cardiopulmonary resuscitation. Am J Emerg Med. 1985;3(2):114-119.

8. Valenzuela TD, Roe DJ, Nichol G, Clark LL, Spaite DW, Hardman RG. Outcomes of rapid defibrillation by security officers after cardiac arrest in casinos. N Engl J Med. 2000;343(17):1206-1209.

9. Valenzuela TD, Roe DJ, Cretin S, Spaite DW, Larsen MP. Estimating effectiveness of cardiac arrest interventions: a logistic regression survival model. Circulation. 1997;96(10):3308-3313.

10. Colquhoun MC. Defibrillation by general practitioners. Resuscitation. 2002;52(2):143-148

11. Ministry of Health: Statistics; Health Facts Singapore. Available from: http://www.moh.gov.sg/mohcorp/. Accessed on 6 July 2009.

12. Ong EHM, Chan YH, Anantharaman V, Lau ST, Lim SH, Seldrup J. Cardiac Arrest and Resuscitation Epidemiology in Singapore (CARE I study). Prehosp Emerg Care. 2003;7:427-433. 
13. Roccia WD, Modic PE, Cuddy MA. Automated external defibrillator use among the general population. J Dent Educ. 2003;67(12):1355-1361.

14. Lubin J, Chung SS, Williams K. An assessment of public attitudes toward automated external defibrillators. Resuscitation. 2004;62(1):43-47.

15. Taniguchi T, Omi W, Inaba H. Attitudes toward automated external defibrillator use in Japan. Resuscitation. 2008;79(2):288-291.

16. Ong ME, Yan X, Lau G, et al. Out-of-hospital cardiac arrests occurring in primary health care facilities in Singapore. Resuscitation. 2007;74(1):38-43.

17. Cummins RO. The "chain of survival" concept: how it can save lives. Heart Dis Stroke. 1992;1(1):43-45.

18. Marenco JP, Wang PJ, Link MS, Homoud MK, Estes NA 3rd. Improving survival from sudden cardiac arrest: the role of the automated external defibrillator. JAMA. 2001;285(9):1193-1200.

19. Herlitz J, Bang A, Axelsson A, Graves JR, Lindqvist J. Experience with the use of automated external defibrillators in out of hospital cardiac arrest. Resuscitation. 1998;37(1):3-7.

20. Ornato JP, McBurnie MA, Nichol G, et al. The Public Access Defibrillation (PAD) trial: study design and rationale. Resuscitation. 2003;56(2):135-147.

21. Davies CS, Colquhoun M, Graham S, Evans T, Chamberlain D. Defibrillators in public places: the introduction of a national scheme for public access defibrillation in England. Resuscitation. 2002;52(1): 13-21.

22. SOS-KANTO study group. Cardiopulmonary resuscitation by bystanders with chest compression only (SOS-KANTO): an observational study. Lancet. 2007;369(9565):920-926.

23. Braslow A, Brennan RT. Layperson CPR: a response to A reappraisal of mouth-to-mouth ventilation during bystander-initiated cardiopulmonary resuscitation. Prehosp Disaster Med. 1999;14(2):113-114.

24. Brenner B, Stark B, Kauffman J. The reluctance of house staff to perform mouth-to-mouth resuscitation in the inpatient setting: what are the considerations? Resuscitation. 1994;28(3):185-193.

25. Brenner BE, Van DC, Lazar EJ, Camargo C. Determinants of physician reluctance to perform mouth-to-mouth resuscitation. J Clin Epidemiol. 2000;53(10):1054-1061.

26. Caves ND, Irwin MG. Attitudes to basic life support among medical students following the 2003 SARS outbreak in Hong Kong. Resuscitation. 2006;68(1):93-100.

27. Jelinek GA, Gennat H, Celenza T, O’Brien D, Jacobs I, Lynch D. Community attitudes towards performing cardiopulmonary resuscitation in Western Australia. Resuscitation. 2001;51(3):239-246.

28. Locke CJ, Berg RA, Sanders AB, et al. Bystander cardiopulmonary resuscitation. Concerns about mouth-to-mouth contact. Arch Intern Med. 1995;155(9):938-943.
29. Ornato JP, Hallagan LF, McMahan SB, Peeples EH, Rostafinski AG. Attitudes of BCLS instructors about mouth-to-mouth resuscitation during the AIDS epidemic. Ann Emerg Med. 1990;19(2):151-156.

30. Shibata K, Taniguchi T, Yoshida M, Yamamoto K. Obstacles to bystander cardiopulmonary resuscitation in Japan. Resuscitation. 2000;44(3):187-193.

31. Taniguchi T, Omi W, Inaba H. Attitudes toward the performance of bystander cardiopulmonary resuscitation in Japan. Resuscitation. 2007;75(1):82-87.

32. Assar D, Chamberlain D, Colquhoun M, et al. Randomised controlled trials of staged teaching for basic life support. 1. Skill acquisition at bronze stage. Resuscitation. 2000;45(1):7-15.

33. Lester CA, Donnelly PD, Assar D. Lay CPR trainees: retraining, confidence and willingness to attempt resuscitation 4 years after training. Resuscitation. 2000;45(2):77-82.

34. Chamberlain D, Smith A, Colquhoun M, Handley AJ, Kern KB, Woollard M. Randomised controlled trials of staged teaching for basic life support: 2. Comparison of CPR performance and skill retention using either staged instruction or conventional training. Resuscitation. 2001;50(1):27-37.

35. Roppolo LP, Pepe PE, Cimon N, et al. Modified cardiopulmonary resuscitation (CPR) instruction protocols for emergency medical dispatchers: rationale and recommendations. Resuscitation. 2005;65(2):203-210.

36. Williams JG, Brice JH, De Maio VJ, Jalbuena T. A simulation trial of traditional dispatcher-assisted CPR versus compressions-only dispatcher-assisted CPR. Prehosp Emerg Care. 2006;10(2):247-253.

37. Woollard M, Smith A, Whitfield R, et al. To blow or not to blow: a randomised controlled trial of compression-only and standard telephone CPR instructions in simulated cardiac arrest. Resuscitation. 2003;59(1):123-131.

38. Hallstrom A, Cobb L, Johnson E, Copass M. Cardiopulmonary resuscitation by chest compression alone or with mouth-to-mouth ventilation. $N$ Engl J Med. 2000;342(21):1546-1553.

39. Hostler D, Guimond G, Callaway C. A comparison of CPR delivery with various compression-to-ventilation ratios during two-rescuer CPR. Resuscitation. 2005;65(3):325-328.

40. Kern KB, Hilwig RW, Berg RA, Sanders AB, Ewy GA. Importance of continuous chest compressions during cardiopulmonary resuscitation: improved outcome during a simulated single lay-rescuer scenario. Circulation. 2002;105(5):645-649.

41. Berg RA, Kern KB, Sanders AB, Otto CW, Hilwig RW, Ewy GA. Bystander cardiopulmonary resuscitation. Is ventilation necessary? Circulation. 1993;88(4 Pt 1):1907-1915.

42. Yu T, Weil MH, Tang W, et al. Adverse outcomes of interrupted precordial compression during automated defibrillation. Circulation. 2002;106(3):368-372. 


\section{Appendix I}

\section{General practitioners' attitudes and knowledge towards defibrillation}

Dear Colleagues,

Of the approximately 15000 deaths that occur in Singapore every year, about 25\% will be from a cardiac cause, of which, some $12 \%-16 \%$ will occur suddenly, outside of a hospital. The purpose of this survey is to find out your opinions regarding certain aspect of managing an out of hospital cardiac arrest. We hope to partner with you to save more of these patients in the future.

Dr Marcus Ong

Consultant, Director of Research and Senior Medical Scientist,

Department of Emergency Medicine, Singapore General Hospital

\section{Demographics}

1. Age:

2. Gender: $\square_{1}$ Male $\square_{2}$ Female

3. Race:

$\square_{1}$ Chinese

$\square_{2}$ Malay

$\square_{3}$ Indian

$\square_{4}$ Others, specify

4. Year obtained MBBS? Year

5. Specialist Training

$\square_{1}$ Family medicine

$\square_{4}$ Others, specify

6. Type of practice?

$\square_{1}$ Family practice

$\square_{2}$ Company practice

$\square_{3}$ Industrial practice

7. Are you BCLS trained?

$\square_{1}$ Yes. If yes, certification still valid? Yes/No

$\square_{2}$ No

8. Are you ACLS trained?

$\square_{1}$ Yes. If yes, certification still valid? Yes/No

$\square_{2}$ No

9. Have you ever attended to cardiac arrest cases?

$\square_{1}$ Yes, how many?

$\square_{2}$ No

10. Does your clinic have any defibrillator?

$\square_{1}$ Yes

11. If your answer is 'YES' to Qn. 10, was the defibrillator being used for any cardiac arrest cases that were attended by you?

$\square$ Yes

$\square_{2}$ No

$\square_{3}$ NA

\section{Knowledge}

12. What do the abbreviations of "AED" represent?
A is for
E is for
D is for

13. AED requires the operator to be able to intepret ECG rhythms. True/False

14. Do you know how to operate an AED?

$\square_{1}$ Yes $\square_{2}$ No 
15. Have you attended any AED training?
$\square_{1}$ Yes
$\square_{2}$ No

16. Besides CPR, which intervention do you think is the most important in saving lives?
$\square_{1}$ Intubation
$\square_{2}$ Giving resuscitation drugs
$\square_{3}$ Defibrillation
$\square_{4}$ Not sure

\section{Attitudes}

17. If an AED is available, would you use it to attend to your cardiac arrest patient?
$\square_{1}$ Yes, go to Qn. 18
$\square_{2}$ No, go to Qn.19

18. Using the scale of 1 to 10,1 being the least and 10 being the most, what is your confidence level in using AED?

[Then go to Qn.20]

19. You would not use the AED because .......
$\square_{1}$ Do not know what is an AED
$\square_{2}$ Do not know how to use an AED
$\square_{3}$ Fear of legal liability
$\square_{4}$ Not confident

20. Are you willing to buy an AED?
$\square_{1}$ Yes, go to Qn. 21
$\square_{2}$ No, go to Qn. 22

21. How much are you willing to pay for an AED?

$\square_{1}<\$ 1,000$

$\square_{2} \$ 1,000-\$ 2,999$

$\square_{3} \$ 3,000-\$ 4,999$

$\square_{4}$ Above $\$ 5,000$

[Then go to Qn.23]

22. Why are you not willing to buy an AED?
$\square_{1}$ Too expensive
$\square_{2}$ Not useful
$\square_{3}$ Difficult to maintain
$\square_{4}$ Unsure of how to use

$\square_{5}$ Others, please specify,

23. What would encourage you to purchase an AED?
$\square_{1}$ Reasonable price
$\square_{2}$ Easy to use
$\square_{3}$ Easy to maintain
$\square_{4}$ Others, specify

24. Are you willing to attend an AED training course, at your own expense?
$\square_{1}$ Yes
$\square_{2}$ No

25. Do you agree that all clinics should be equipped with an AED?
$\square_{1}$ Yes
$\square_{2}$ No

26. Would you support legislation to make defibrillators compulsory equipment for all clinics?
$\square_{1}$ Yes
$\square_{2}$ No

27. Would you support/participate in community CPR/AED project?
$\square_{1}$ Yes
$\square_{2}$ No

\section{Chest compression-only resuscitation vs. cardio-pulmonary resuscitation}

28. Would you perform mouth-to-mouth ventilation during CPR?

$$
\square_{1} \text { Yes }
$$

$\square_{2}$ No 
29. Which method of resuscitation would you prefer?

$\square_{1}$ Chest compression-only. Reason:
$\square_{\mathrm{a}}$ As effective as CPR
$\square_{\mathrm{b}}$ Easier to learn
$\square_{\mathrm{c}}$ Unwilling to do mouth-to-mouth
$\square_{\mathrm{d}}$ Others, specify

$\square_{2}$ Both ventilation and chest compression. Reason:
$\square_{\mathrm{a}}$ More effective
$\square_{\mathrm{b}}$ Confident of CPR techniques

$\square_{\mathrm{c}}$ Recommended by National Resuscitation Council

$\square_{\mathrm{d}}$ Others, specify

\section{Publish your work in this journal}

Open Access Emergency Medicine is an international, peer-reviewed, open access journal publishing original research, reports, editorials, reviews and commentaries on all aspects of emergency medicine. The manuscript management system is completely online and includes a very quick and fair peer-review system, which is all easy to use.

Visit http://www.dovepress.com/testimonials.php to read real quotes from published authors. 